\title{
BMJ Open Occupational difference in use of heated tobacco products: a cross-sectional analysis of retail workers in Japan
}

\author{
Enkhtuguldur Myagmar-Ochir, ${ }^{1}$ Makiko Kaneko, ${ }^{2}$ Kiyomi Tomiyama, ${ }^{2}$ \\ Masayoshi Zaitsu (D , , Shuichi Watanabe, ${ }^{2}$ Yoshitaka Nishino, ${ }^{1}$ Kyo Takahashi, ${ }^{1}$ \\ Yasuo Haruyama, ${ }^{3}$ Gen Kobashi ${ }^{1}$
}

To cite: Myagmar-0chir E, Kaneko M, Tomiyama K, et al. Occupational difference in use of heated tobacco products: a cross-sectional analysis of retail workers in Japan. BMJ Open 2021;11:e049395. doi:10.1136/ bmjopen-2021-049395

- Prepublication history and additional supplemental material for this paper are available online. To view these files, please visit the journal online (http://dx.doi.org/10.1136/ bmjopen-2021-049395).

Received 26 January 2021 Accepted 10 August 2021

\section{Check for updates}

(C) Author(s) (or their employer(s)) 2021. Re-use permitted under CC BY-NC. No commercial re-use. See rights and permissions. Published by BMJ.

${ }^{1}$ Department of Public Health, Dokkyo Medical University School of Medicine, Shimotsuga-gun, Tochigi, Japan ${ }^{2}$ Division of Health Support, Department Store Health Insurance Association, Tokyo, Japan

${ }^{3}$ Integrated Research Faculty for Advanced Medical

Sciences, Dokkyo Medical University School of Medicine, Shimotsuga-gun, Tochigi, Japan

Correspondence to

Masayoshi Zaitsu;

m-zaitsu@dokkyomed.ac.jp

\section{ABSTRACT}

Objective Although heated tobacco products (HTPS) have become popular worldwide, research on occupational differences in smoking HTPs remains scarce. We aimed to examine the prevalence of smoking HTPs among a working population in Japan.

Setting, design and participants In 2018, we conducted a cross-sectional study comprised of 7714 retail business workers in the service industry in Japan.

Primary and secondary outcome measures For the definition of smoking HTPs, we identified current HTP smokers who only smoked HTPs, using five mutual categories of current smoking status (never, former, HTPs only, combustible cigarettes only and dual smokers who smoked both combustible cigarettes and HTPs). Occupational classes were classified into office workers (eg, upper non-manual workers) and other workers. ORs and $95 \%$ Cls of office workers were estimated for HTP usage, adjusted for age, sex, employment type and cigarette smoking-related health knowledge.

Results The overall prevalence of smoking HTPs was $3.0 \%$ (male $5.0 \%$, female $2.2 \%$ ). The prevalence of HTP smokers differed across occupational classes $(5.6 \%$ in office workers vs $2.5 \%$ in others; $p<0.05$ ). Compared with other workers, the adjusted odds of office workers for smoking HTPs remained elevated (OR: 1.97, 95\% Cl: 1.40 to 2.77). Sensitivity analyses with workers of all smoking status showed the same pattern. When stratified by sex, the occupational difference only remained significant in male workers.

Conclusions We found a positive occupational difference in smoking HTPs, particularly among male workers in the retail sector in Japan. National tobacco control should explicitly address this occupational gap and further encourage individuals to quit smoking.

\section{INTRODUCTION}

Heated tobacco products (HTPs) are smoking devices that heat tobacco sticks to produce aerosols containing nicotine and other chemicals for inhalation. ${ }^{12}$ The widespread use of HTPs represents an emerging public health concern. After the initial marketing of IQOS (a brand of HTPs) in Japan and Italy in 2014, HTP usage rapidly spread to more than 30 countries. $^{2}$ In Japan, HTP brands

\section{Strengths and limitations of this study}

- This is the first study to examine occupational differences in the prevalence of smoking heated tobacco products (HTPs) among a sizeable working population in Japan.

- This study analysed a sample of over 7700 retail business workers reporting their HTP usage and occupational class in 2018.

- This study adjusted for variables that might affect occupational differences in smoking HTPs.

- Limitations include a cross-sectional design, which does not allow firm conclusions regarding causal mechanisms.

IQOS and Ploom Tech (launched in March 2016) and Glo (launched in December 2016) are currently available, ${ }^{2}$ and the market share was accounted for $21 \%$ in total tobacco sales in 2018. ${ }^{3}$ The prevalence of HTP usage was found to have reached approximately $8 \%$ in men and 2\% in women in 2018. ${ }^{4}$ Although limited studies on HTPs usage are available, the prevalence has begun to increase worldwide (approximately 1.4\% in Italy in 2017 and $2.9 \%$ in Guatemala adolescents in 2020) ${ }^{56} \mathrm{In}$ some Asian countries, the market for HTPs remains relatively small, and HTPs are not officially retailed in China and Hong Kong. ${ }^{7}$ Although the impression of HTPs as a healthy alternative is promoted by direct-to-consumer and indirect-to-consumer advertising of HTPs compared with conventional combustible cigarettes (eg, reduced harmfulness and a smoke-free image), ${ }^{8}$ there is accumulating evidence for HTP-related adverse effects on health, including acute respiratory diseases and cardiovascular events. ${ }^{9} 10$ In addition, the long-term safety of HTPs has not been proven.

In Japan, the use of HTPs may be related to social patterning. For instance, the distribution of HTP usage has been found to differ 
across sex and age: men and younger people in their $20 \mathrm{~s}$ and 30s were found to be more likely to smoke HTPs compared with their female and older counterparts, ${ }^{11-13}$ which has been proposed to be partly attributable to a popular television programme. ${ }^{2}$ Furthermore, several studies have suggested that a socioeconomic difference for the use of HTPs should be investigated. ${ }^{411} 1314$ A recent online cross-sectional survey suggested a potential 'positive' socioeconomic difference in HTP usage. ${ }^{11}$ In that study, individuals with higher socioeconomic status (SES), in terms of educational attainment and household income, were more likely to smoke HTPs compared with their lower SES counterparts. However, the occupational difference, one of three fundamental SES indicators (education, income, and occupation), remains unclear in relation to the use of HTPs.

The present study aimed to examine the overall and sex-specific prevalence of smoking HTPs among a sizeable working population in the retail sector, a common service industry sector in Japan. We sought to examine whether higher occupational class is associated with higher prevalence of smoking HTPs.

\section{METHODS}

\section{Data setting}

Among a working population of the Department Store Health Insurance Association in the retail sector, we conducted a cross-sectional survey about smoking and related health knowledge in August 2018. As a baseline survey, this study was intended to capture a broad overview of occupational factors associated with smoking HTPs. The survey instrument was a self-report questionnaire about smoking behaviours (smoking status and duration of smoking) and HTPs. The survey also asked respondents about their knowledge of smoking-related adverse effects such as cancer and cardiovascular risks. We distributed 8638 questionnaires to all workers in the working population of department stores; 7837 self-reported questionnaires were collected (response rate, 90.7\%). For each participant, the Department Store Health Insurance Association mutually linked collected data to individual basic demographics (age and sex) and current job information, including occupational class (eg, managerial and clerical workers) and employment type (full-time or part-time workers). We obtained a deidentified data set from the Department Store Health Insurance Association. Written informed consent was obtained and participants received a prepaid card with a value of 300 Japanese yen (approximately US \$3) after the survey for their cooperation.

From 7837 study participants, we excluded data from participants with missing information $(\mathrm{n}=123,1.6 \%)$, which gave a total of 7714 study participants (2215 men and 5499 women; mean age, 46.6 (SD: 12.8) years) for analysis.

\section{Main outcome of HTP usage}

The primary outcome was to assess the prevalence of smoking HTPs currently in the retail sector in Japan.
In the questionnaire, HTPs were described as 'tobacco', in accord with the Tobacco Business Act in Japan. We cited the IQOS, Glo and Ploom Tech as HTPs with pictures because these products were commercially available in Japan in 2018. The study participants chose one status for smoking (never, former, sometimes or every day) from the question, 'Do you currently smoke?' If they answered 'sometimes' or 'every day,' we defined them as current smokers. For current smokers, we distinguished between smoking combustible cigarettes, HTPs or both, using the following question: "Which type(s) of tobacco do you smoke? Please choose all options that apply from the following: combustible cigarettes, IQOS, Glo, or Ploom Tech'. Based on this protocol, we classified participants into three current smoking status categories (never, former and current). We also divided current smokers using HTPs, ultimately identifying five mutually exclusive groups, as follows.

1. Never smokers

2. Former smokers

3. HTP smokers, who currently smoke HTPs only

4. Combustible cigarette smokers, who currently smoke combustible cigarettes only

5. Dual smokers, who currently smoke both combustible cigarettes and HTPs

To clarify and simplify the context of using HTPs, we defined smoking HTPs by identifying HTPs smokers only (but excluding dual smokers). Following the rapid rise in prevalence of HTPs after 2016 in Japan, ${ }^{2}$ most HTP smokers were found to have switched from combustible cigarettes, after a long history of smoking ( $\geq 15$ years of smoking history, 140 of 229 participants, $61.1 \%$ ).

\section{Occupational information, smoking-related health knowledge,} and other variables

According to the Erikson-Goldthorpe-Portocarero scheme, an internationally valid occupational class measurement for SES ${ }^{15}$ and previous studies that adapted the Erikson-Goldthorpe-Portocarero scheme for Japanese occupational classes, ${ }^{11} 1617$ we defined two groups of occupational classes: office workers (managerial and professional workers, $5.2 \%(\mathrm{n}=399)$ and clerical workers, $9.4 \%(\mathrm{n}=723)$ ) and other workers (service workers, $78.4 \%(\mathrm{n}=6047)$ and manual workers, $7.1 \%(\mathrm{n}=545))$. In the Erikson-Goldthorpe-Portocarero scheme, clerical workers (classified as lower non-manual workers) are considered as a lower job class group compared with managerial and professional workers (classified as upper non-manual workers). However, because clerical workers have been reported to have more favourable health outcomes in terms of mortality and cancer survival compared with managerial and professional workers in Japan, ${ }^{16} 18$ we classified clerical workers into the office worker group.

For a broad indicator of health knowledge that might affect risky behaviour of smoking HTPs (because the long-term safety of HTPs has not been proven), study participants were asked whether they knew about the 
link between cigarette smoking and each of five common diseases: asthma (yes/no), lung cancer (yes/no), stroke (yes/no), angina/myocardial infarction (yes/no) and periodontal disease (yes/no). By calculating how many links they knew about, we obtained a total sum score of smoking-related health knowledge, a continuous variable ranging from 0 (did not know about any links to diseases) to 5 (knew about all links to diseases). Because the study participants may have learnt about all of the links to diseases through public education provided by the government, ${ }^{19}$ we handled all diseases equally without using different weights.

In our analytical model for explaining the association between occupational class and smoking HTPs, potential confounding variables included basic demographics (age and sex) and employment type (full-time or parttime workers). ${ }^{11}$ As a potential mediating variable that could explain the association (but not be a confounding factor), we included the total sum score of smokingrelated health knowledge as an explanatory variable in our regression model. Although HTP-related risks for common chronic diseases have not been established and health-related knowledge regarding cigarette smoking might not provide a complete substitute for the potential motivations for smoking HTPs, we empirically employed this indicator as a potential behavioural mediator.

\section{Statistical analysis}

Descriptive analyses were used to report the background characteristics of the study participants and the prevalence of HTP usage.

Next, compared with the other workers, we estimated ORs and 95\% CIs of office workers for HTP usage using logistic regression. In multivariable regression analyses, we adjusted for age, sex and employment type (full-time/ part-time) (model 1$)$. In model 2 , we additionally adjusted for smoking-related health knowledge as a continuous variable. Analyses were also stratified by sex.

Furthermore, we used all 7714 study participants, which also included former smokers, combustible cigarette smokers and dual smokers. To examine the association for each smoking status against occupational classes, we estimated multinomial ORs using multinomial logistic regression. ${ }^{11}$ Again, we adjusted for age, sex and employment type in model 1 and additionally adjusted for smoking-related health knowledge in model 2. Analyses were also stratified by sex. For a supplementary analysis within HTP smokers, we explored potential reasons for smoking HTPs and health attitudes regarding HTPs.

In addition, to further elucidate occupational differences in use of HTPs, we performed sensitivity analyses using two different occupational categories: (a) upper non-manual workers (ie, managerial and professional workers) versus service and manual workers and (b) upper non-manual workers versus clerical, service and manual workers combined.

All p-values were both sided and the alpha level was set at 0.05. Data were analysed using SPSS V.26.0 (SPSS, Chicago, USA).

\section{Patient and Public Involvement}

No patients or the public involved.

\section{RESULTS}

Of the total 7714 study participants, the prevalence of HTPs was $3.0 \%$ (male $5.0 \%$, female $2.2 \%$; table 1 ). The prevalence of HTPs smokers was greater in a younger population aged in their 30 s and 40 s than an older population aged in their $60 \mathrm{~s}$ and above. The prevalence of HTPs smokers differed across occupational classes and employment types, respectively (all $\mathrm{p}<0.05$, figure 1 ).

Table 1 Background characteristics of a large working cohort of department stores in Japan

\begin{tabular}{|c|c|c|c|}
\hline \multirow[b]{2}{*}{ Characteristics } & \multicolumn{3}{|c|}{$\mathbf{N}(\%)$ or mean (SD)* } \\
\hline & Total $(n=7714)$ & Male $(n=2215)$ & Female $(n=5499)$ \\
\hline Age, mean (SD) & $46.6(12.8)$ & $40.2(13.7)$ & $49.2(11.4)$ \\
\hline Full-time employment & $1800(23.3)$ & $1349(60.9)$ & $451(8.2)$ \\
\hline \multicolumn{4}{|l|}{ Current smoking status } \\
\hline Former smokers & $1428(18.5)$ & $466(21.0)$ & $962(17.5)$ \\
\hline Current smoker & $1706(22.1)$ & 738 (33.3) & $968(17.6)$ \\
\hline Combustible cigarette smokers & $1217(15.8)$ & $505(22.8)$ & $712(12.9)$ \\
\hline HTPs smokers & 229 (3.0) & $110(5.0)$ & $119(2.2)$ \\
\hline Dual smokers $†$ & $260(3.4)$ & $123(5.6)$ & $137(2.5)$ \\
\hline
\end{tabular}

${ }^{*}$ Percentage may not total 100 due to rounding.

†Dual smokers are those who currently smoke both combustible cigarettes and HTPs.

HTPs, heated tobacco products.; 


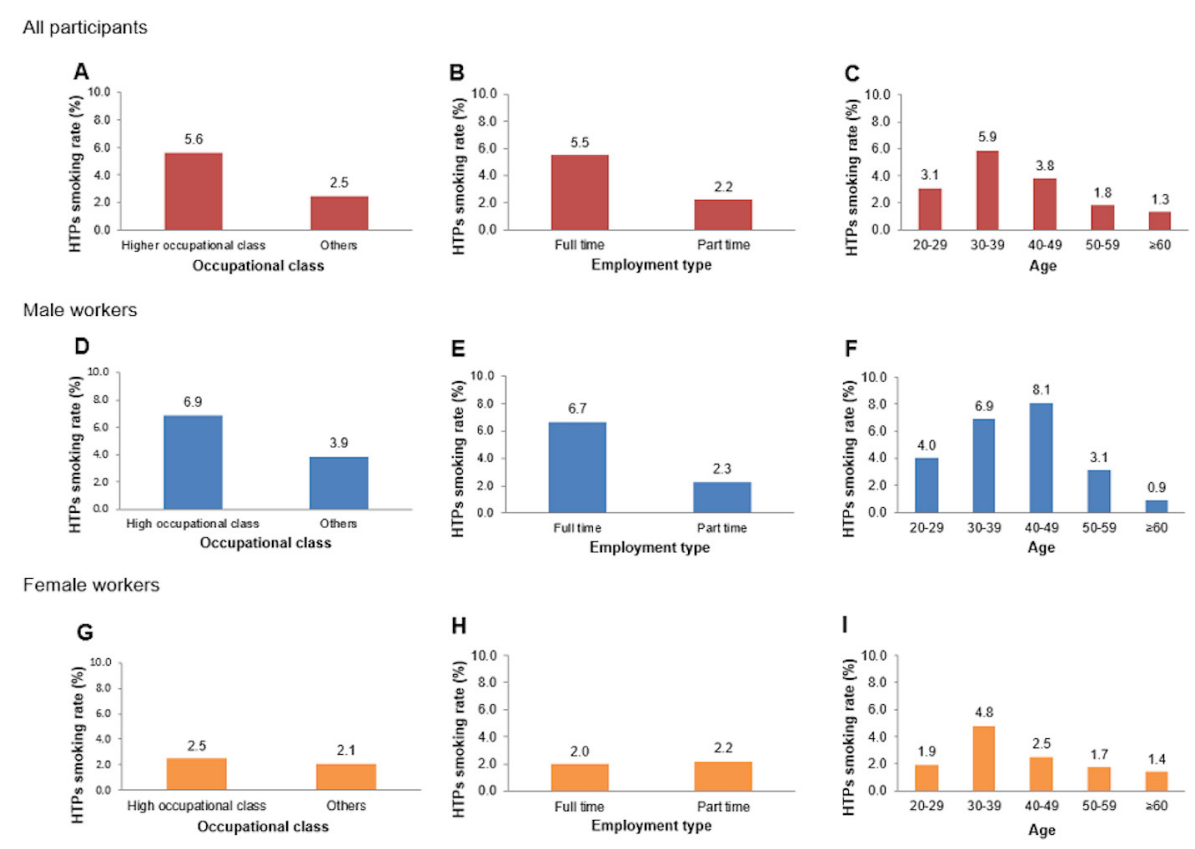

Figure 1 Prevalence of heated tobacco smokers across various background characteristics in the cohort. Each bar shows the prevalence of heated tobacco smokers within specific background characteristics. HTP, heated tobacco products.

Occupational differences only remained significant in male workers when stratified by sex (figure 1).

The percentage of current smokers among office workers was higher than that among other workers $(p<0.001)$ (table 2). Among male office workers, the prevalence of individuals who had ever smoked or were HTP smokers was again greater, and the prevalence of current smokers tended to be greater (table 2). Meanwhile, none of the smoking status groups differed across occupational classes among female workers.

Overall, most of the specific disease knowledge was insufficient, except for lung cancer, and most of the study participants did not know about the link between smoking and cardiovascular diseases (table 2).

In regression analyses, although the background characteristics differed across occupation and smoking status (table 2 and online supplemental table S1), a positive occupational difference for HTP usage was observed in multivariable logistic regression (model 1, table 3). Even after controlling for smoking-related health knowledge (model 2), the elevated odds remained significant (OR: $1.97,95 \%$ CI: 1.40 to 2.77 , table 3 ). In addition, the odds of full-time employment and smoking-related health knowledge were significantly elevated (model 2, table 3 ). However, for the sex-specific association, the occupational difference only remained significant in male workers (table 3).

In addition, in a sensitivity analysis including all types of smokers, office workers were more likely to smoke HTPs (table 4), and the observed patterns were almost identical. In sensitivity analyses using different occupational categories, the observed patterns were almost identical: (a) compared with service and manual workers, the OR of upper non-manual workers for smoking HTPs was 3.54
(95\% CI: 2.16 to 5.80, model 2) and (b) compared with clerical, service and manual workers combined, the OR of upper non-manual workers for smoking HTPs was 3.04 (95\% CI: 1.88 to 4.89, model 2). Among HTP smokers, the dominant reason for smoking HTPs was reduced odour and smoke, rather than taking care of others (ie, not to bother others) or considering health-related aspects (online supplemental table S2).

\section{DISCUSSION}

Using a large working population in the retail sector in Japan, we first found that the prevalence of HTP usage was at least $5 \%$ in male workers and $2 \%$ in female workers, with a positive occupational difference for smoking HTPs. Male workers in the higher occupational class in this population were more likely to be ever smokers, with a higher prevalence of smoking HTPs. In addition, no significant occupational difference was observed in current smoking status among female workers. Public awareness was generally insufficient regarding tobacco-induced health disadvantages, despite contemporary public education.

Cigarette smokers, particularly those in high occupational classes, should fundamentally be encouraged to quit smoking, and not to use HTPs. ${ }^{20}$ The majority of HTP smokers in the current study $(>60 \%)$ were former combustible cigarette smokers, and office workers were more likely to have ever been smokers than their occupational counterparts, consistent with a well-known contemporary pattern in Japan. ${ }^{21} 22$ Additionally, among HTP smokers, the dominant reason for smoking HTPs was reduced odour or reduced smoke.

Behavioural and environmental aspects associated with the workplace in Japan may also play a role in the pattern 
Table 2 Occupational differences in smoking status and cigarette smoking-related heath knowledge stratified by sex

\begin{tabular}{|c|c|c|c|}
\hline \multirow[b]{2}{*}{ Characteristics } & \multicolumn{2}{|c|}{ N (\%) or mean (SD) } & \multirow[b]{2}{*}{ P value* } \\
\hline & Office workers & Others & \\
\hline Total & $n=1122$ & $\mathrm{n}=6592$ & \\
\hline Age, mean (SD) & $45.5(11.8)$ & $46.8(12.9)$ & 0.001 \\
\hline Female & $325(29.0)$ & $5174(78.5)$ & $<0.001$ \\
\hline Full-time employment & $466(41.5)$ & $1334(20.2)$ & $<0.001$ \\
\hline \multicolumn{4}{|l|}{ Current smoking status } \\
\hline Never smokers & $518(46.2)$ & $4062(61.6)$ & $<0.001$ \\
\hline Former smokers & $273(24.3)$ & $1155(17.5)$ & $<0.001$ \\
\hline Current smoker & $331(29.5)$ & $1375(20.9)$ & $<0.001$ \\
\hline Combustible cigarette smokers & $222(19.8)$ & $995(15.1)$ & $<0.001$ \\
\hline Dual smokers & $46(4.1)$ & $214(3.2)$ & 0.143 \\
\hline HTPs smokers & $63(5.6)$ & $166(2.5)$ & $<0.001$ \\
\hline Total score, mean (SD)† & $2.9(1.4)$ & $2.7(1.3)$ & $<0.001$ \\
\hline Asthma & $794(70.8)$ & $4581(69.5)$ & 0.391 \\
\hline Lung cancer & $1042(92.9)$ & $6150(93.3)$ & 0.600 \\
\hline Stroke & $509(45.4)$ & $2671(40.5)$ & 0.002 \\
\hline Angina/myocardial infarction & $540(48.1)$ & $2707(41.1)$ & $<0.001$ \\
\hline Periodontal disease & $342(30.5)$ & $1789(27.1)$ & 0.021 \\
\hline Male & $\mathrm{n}=797$ & $\mathrm{n}=1418$ & \\
\hline Age, mean (SD) & $45.4(11.8)$ & $37.4(13.9)$ & $<0.001$ \\
\hline Full-time employment & $426(53.5)$ & $923(65.1)$ & $<0.001$ \\
\hline \multicolumn{4}{|l|}{ Current smoking status } \\
\hline Never smokers & $304(38.1)$ & 707 (49.9) & $<0.001$ \\
\hline Former smokers & $219(27.5)$ & $247(17.4)$ & $<0.001$ \\
\hline Current smoker & $274(34.4)$ & $464(32.7)$ & 0.427 \\
\hline Combustible cigarette smokers & $178(22.3)$ & $327(23.1)$ & 0.696 \\
\hline Dual smokers & $41(5.1)$ & $82(5.8)$ & 0.529 \\
\hline HTPs smokers & $55(6.9)$ & $55(3.9)$ & 0.002 \\
\hline Total score, mean (SD) & $3.0(1.4)$ & $2.6(1.4)$ & $<0.001$ \\
\hline Asthma & $574(72.0)$ & $908(64.0)$ & $<0.001$ \\
\hline Lung cancer & $752(94.4)$ & $1286(90.7)$ & 0.002 \\
\hline Stroke & $385(48.3)$ & $589(41.5)$ & 0.002 \\
\hline Angina/myocardial infarction & $411(51.6)$ & $507(35.8)$ & $<0.001$ \\
\hline Periodontal disease & $261(32.7)$ & $453(31.9)$ & 0.699 \\
\hline Female & $n=325$ & $\mathrm{n}=5174$ & \\
\hline Age, mean (SD) & $45.7(11.8)$ & $49.4(11.4)$ & $<0.001$ \\
\hline Full-time employment & $40(12.3)$ & $411(7.9)$ & 0.005 \\
\hline \multicolumn{4}{|l|}{ Current smoking status } \\
\hline Never smokers & $214(65.8)$ & $3355(64.8)$ & 0.713 \\
\hline Former smokers & $54(16.6)$ & $908(17.5)$ & 0.667 \\
\hline Current smoker & $57(17.5)$ & $911(17.6)$ & 0.975 \\
\hline Combustible cigarette smokers & 44 (13.5) & $668(12.9)$ & 0.744 \\
\hline Dual smokers & $5(1.5)$ & $132(2.6)$ & 0.256 \\
\hline HTPs smokers & $8(2.5)$ & $111(2.1)$ & 0.704 \\
\hline Total score, mean (SD) & $2.6(1.4)$ & $2.7(1.3)$ & 0.069 \\
\hline
\end{tabular}


Table 2 Continued

\begin{tabular}{cccc}
\hline & $\mathbf{N}(\%)$ or mean (SD) & & \\
\cline { 2 - 3 } Characteristics & Office workers & Others & Palue* \\
\hline Asthma & $220(67.7)$ & $3673(71.0)$ & 0.205 \\
Lung cancer & $290(89.2)$ & $4864(94.0)$ & 0.001 \\
Stroke & $124(38.2)$ & $2082(40.2)$ & 0.457 \\
Angina/myocardial infarction & $129(39.7)$ & $2200(42.5)$ & 0.317 \\
Periodontal disease & $81(24.9)$ & $1336(25.8)$ & 0.719 \\
\hline
\end{tabular}

${ }^{*} \mathrm{P}$ values for $\mathrm{t}$-test or $\chi^{2}$ test.

†Total scores were created by summing up each link known.

HTPs, heated tobacco products.

of results we observed. In contrast to the contemporary pattern seen in Western countries, higher occupational class workers are likely to experience greater job stress, potentially stemming from overtime work, hierarchical corporate culture in Japanese companies and a strongly emphasised concept of hospitality to meet customers' expectations. ${ }^{23}$ Previous studies suggest that male fulltime workers experience higher levels of job stress, ${ }^{24}$ and occupational stress has long been assumed to lead to the development of stress coping responses, such as smoking. ${ }^{25}$ In the current study, it might be expected that male workers in higher occupational positions, particularly those in the service sector, ${ }^{23} 2627$ are more likely to smoke, irrespective of tobacco products.
In addition to HTP product advertisements promoting a clean image of reduced harmfulness, ${ }^{8}$ other behavioural drives for HTPs smoking may exist in Japan. For instance, an increase of tobacco ads has been observed in $\operatorname{Japan}^{28}$ and tobacco industry widely promotes HTPs (eg, online stores and convenience stores) ${ }^{29}$ Economic dimensions of HTPs may also support the positive occupational difference we observed. For instance, the price of an HTP device was reported to be 6-18 times more expensive than a pack of cigarettes in $2018,{ }^{30}$ and the prevalence of HTP smokers was higher among full-time workers (ie, affluent workers) in the present study. In addition, the higher price might be related to subjective impressions

Table 3 ORs for heated tobacco smokers against occupational class and other factors

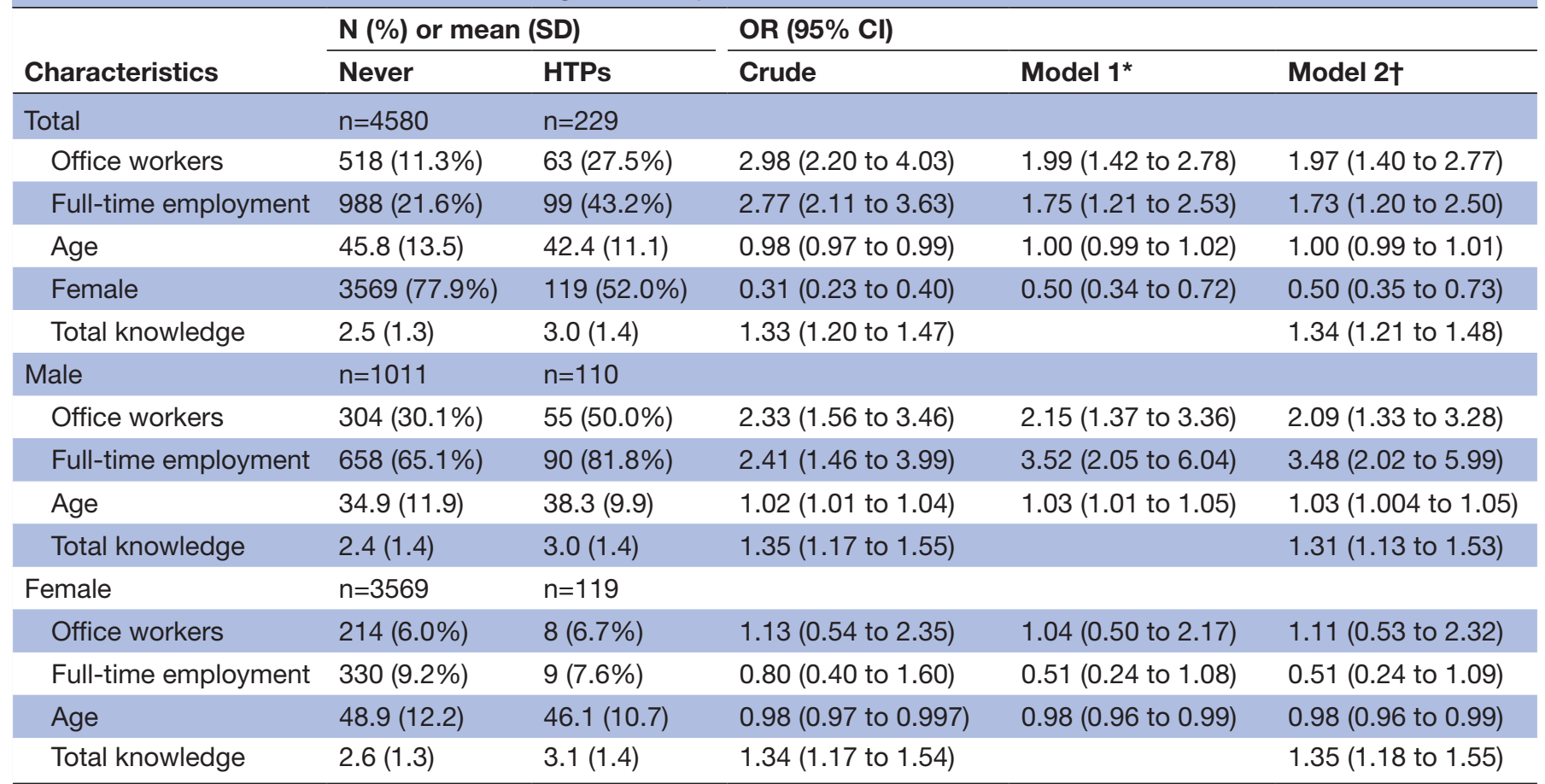

${ }^{*}$ ORs for heated tobacco smokers against occupational class were estimated with unconditional logistic regression, adjusted for age, sex and employment type.

†Additional adjustment for smoking-related health knowledge.

HTPs, heated tobacco products. 
Table 4 Multinomial ORs for each smoking status in high occupational class workers

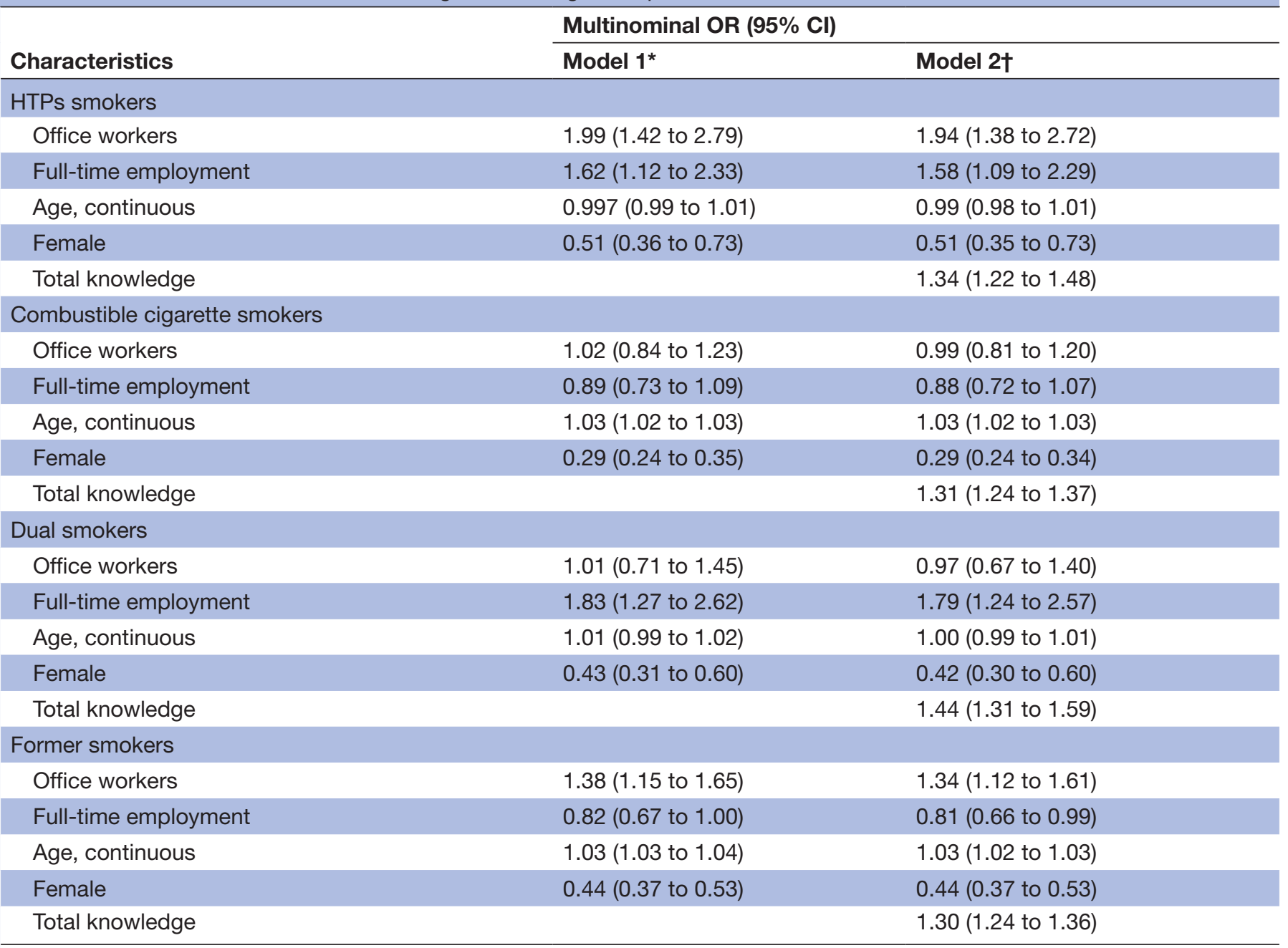

${ }^{*}$ Adjusted for age, sex and employment type.

†Additional adjustment for smoking-related health knowledge.

HTP, heated tobacco product.

of high-quality products, which could act as another potential driver for using HTPs.

Several limitations of the current study should be noted. First, our cross-sectional design does not allow firm conclusions regarding the causal mechanisms underlying the relationship between occupation and HTP usage. Additionally, we were not able to assess other relevant SES indicators (ie, educational attainment and income) in this working population. However, reverse causality appears to be unlikely because occupational classes are a fundamental SES indicator, and studies suggest a potential SES gap in smoking HTPs. ${ }^{11}$ Second, although our data were extracted from a sizeable working population in the retail sector, the numbers of male and female workers were not balanced. In addition, the study participants only included workers in department stores, thereby limiting the generalisability of our findings. Despite these limitations, the current study is one of the most extensive investigations of the use of HTPs in Japan. Third, our self-reported questionnaires may have been subject to under-reporting of HTP usage. Smoking duration, amount (number of heat sticks/cartridge per day) and intensity were not separately available for combustible cigarettes and HTPs. Thus, these limitations might have introduced potential misclassifications in smoking categories. However, previous studies have supported the validity of selfreported smoking status and tobacco use. ${ }^{31}$ Fourth, we intended to capture a broad overview of the relationship between occupation and HTPs. Thus, data for potential acute and chronic clinical outcomes were not available. In addition, due to the limitations of our data set, we were unable to completely assess how health knowledge related to HTPs is associated with smoking HTPs. Additionally, it remains unclear whether the observed positive occupational difference for HTP usage is associated with overall mortality and cardiovascular risk, combined with inflammatory and oxidative stress (eg, C-reactive protein and urinary 8-hydroxydeoxyguanosine) ${ }^{32}{ }^{33}$ Despite these limitations, the strengths of the current study included a large sample size for overall and female participants, 
providing the first report of an occupational difference in smoking HTPs with a robust occupational indicator. ${ }^{11} 1617$

Finally, our results suggest that HTP smoking is getting prevalent, particularly among higher-SES males in Japan. Previous studies reported a potential occupational difference in smoking HTPs among men but not among women, ${ }^{411}$ which are in line with our result. Higher occupational workers are reported to have higher overall mortality and cardiovascular risk. ${ }^{16}{ }^{23}$ In addition, the long-term safety of HTPs has not been proven, and there is accumulating evidence for HTP-related adverse effects on health. ${ }^{9} 10$ Therefore, further public education on tobacco control, including population approaches and high-risk approaches, should remain a high priority for combustible cigarette and HTPs smoking.

In conclusion, the current findings indicated that higher occupational class is associated with a higher prevalence of smoking HTPs, particularly among male retail workers in the service industry in Japan. Public awareness of tobacco-related health impacts is currently insufficient. Hence, national tobacco control should explicitly address this occupational gap and further encourage individuals to quit smoking.

Acknowledgements We thank Benjamin Knight, MSc., from Edanz Group (https:// en-author-services.edanzgroup.com/ac) for editing a draft of this manuscript.

Contributors EM, MZ and YH designed the study. MK, KTo and SW created the data set. EM, YN and $M Z$ analysed the data. EM wrote the first draft of the manuscript. MK, KTo, MZ, SW, YN, KTa, YH and GK commented on the manuscript. All authors read and approved the final manuscript.

Funding This work was supported in part by Health, Labour and Welfare Sciences Research Grants (20FA1005) and Japan Society for the Promotion of Science (JSPS KAKENHI JP18K17351).

Competing interests None declared.

Patient consent for publication Not required.

Ethics approval The study was approved by the Ethics Committee of Dokkyo Medical University (Protocol Number 30007).

Provenance and peer review Not commissioned; externally peer reviewed.

Data availability statement № data are available.

Supplemental material This content has been supplied by the author(s). It has not been vetted by BMJ Publishing Group Limited (BMJ) and may not have been peer-reviewed. Any opinions or recommendations discussed are solely those of the author(s) and are not endorsed by BMJ. BMJ disclaims all liability and responsibility arising from any reliance placed on the content. Where the content includes any translated material, BMJ does not warrant the accuracy and reliability of the translations (including but not limited to local regulations, clinical guidelines, terminology, drug names and drug dosages), and is not responsible for any error and/or omissions arising from translation and adaptation or otherwise.

Open access This is an open access article distributed in accordance with the Creative Commons Attribution Non Commercial (CC BY-NC 4.0) license, which permits others to distribute, remix, adapt, build upon this work non-commercially, and license their derivative works on different terms, provided the original work is properly cited, appropriate credit is given, any changes made indicated, and the use is non-commercial. See: http://creativecommons.org/licenses/by-nc/4.0/.

ORCID iD

Masayoshi Zaitsu http://orcid.org/0000-0001-7616-355X

\section{REFERENCES}

1 Smith MR, Clark B, Lüdicke F, et al. Evaluation of the tobacco heating system 2.2. Part 1: description of the system and the scientific assessment program. Regul Toxicol Pharmacol 2016;81 Suppl 2:S17-26.

2 Tabuchi T, Gallus S, Shinozaki T, et al. Heat-not-burn tobacco product use in Japan: its prevalence, predictors and perceived symptoms from exposure to secondhand heat-not-burn tobacco aerosol. Tob Control 2018;27:e25-33.

3 Craig LV, Yoshimi I, Fong GT, et al. Awareness of marketing of heated tobacco products and cigarettes and support for tobacco marketing restrictions in Japan: findings from the 2018 international tobacco control (ITC) Japan survey. Int J Environ Res Public Health 2020;17:8418.

4 Kinjo A, Kuwabara Y, Fujii M, et al. Heated tobacco product smokers in Japan identified by a population-based survey. J Epidemiol 2020;30:547-55.

5 Liu X, Lugo A, Spizzichino L, et al. Heat-not-burn tobacco products: concerns from the Italian experience. Tob Control 2019;28:113-4.

6 Gottschlich A, Mus S, Monzon JC, et al. Cross-sectional study on the awareness, susceptibility and use of heated tobacco products among adolescents in Guatemala City, Guatemala. BMJ Open 2020;10:e039792.

7 Wu YS, Wang MP, Ho SY, et al. Heated tobacco products use in Chinese adults in Hong Kong: a population-based cross-sectional study. Tob Control 2020;29:277-81.

8 Hair EC, Bennett M, Sheen E, et al. Examining perceptions about IQOS heated tobacco product: consumer studies in Japan and Switzerland. Tob Control 2018;27:s70-3.

9 Simonavicius E, McNeill A, Shahab L, et al. Heat-not-burn tobacco products: a systematic literature review. Tob Control 2019;28:582-94.

10 Chung SJ, Kim B-K, Oh JH, et al. Novel tobacco products including electronic cigarette and heated tobacco products increase risk of allergic rhinitis and asthma in adolescents: analysis of Korean youth survey. Allergy 2020;75:1640-8.

11 Igarashi A, Aida J, Kusama T, et al. Heated tobacco products have reached younger or more affluent people in Japan. $J$ Epidemiol 2021;31:187-93.

12 McKelvey K, Popova L, Kim M, et al. Heated tobacco products likely appeal to adolescents and young adults. Tob Control 2018;27:s41-7.

13 Sutanto E, Miller C, Smith DM, et al. Prevalence, use behaviors, and preferences among users of heated tobacco products: findings from the 2018 ITC Japan survey. Int J Environ Res Public Health 2019:16:4630.

14 Adamson J, Kanitscheider C, Prasad K, et al. Results from a 2018 cross-sectional survey in Tokyo, Osaka and Sendai to assess tobacco and nicotine product usage after the introduction of heated tobacco products (HTPs) in Japan. Harm Reduct $J$ 2020;17:32.

15 Erikson R, Goldthorpe JH, Portocarero L. Intergenerational class mobility and the convergence thesis: England, France and Sweden. 1979. Br J Sociol 2010;61 Suppl 1:185-219.

16 Tanaka H, Nusselder WJ, Bopp M, et al. Mortality inequalities by occupational class among men in Japan, South Korea and eight European countries: a national register-based study, 1990-2015. J Epidemiol Community Health 2019;73:750-8.

17 Tanaka H, Mackenbach JP, Kobayashi Y. Widening socioeconomic inequalities in smoking in Japan, 2001-2016. J Epidemiol 2021;31:369-77.

18 Zaitsu M, Lee H-E, Lee S, et al. Occupational disparities in bladder cancer survival: a population-based cancer registry study in Japan. Cancer Med 2020;9:894-901.

19 Ministry of Health, Labour and Welfare. Tobacco and health information page. Available: https://www.mhlw.go.jp/stf/ seisakunitsuite/bunya/kenkou_iryou/kenkou/tobacco/index.html

20 Link BG, Phelan J. Social conditions as fundamental causes of disease. J Health Soc Behav 1995;Spec No:80-94.

21 Lahelma E, Lallukka T, Laaksonen M, et al. Social class differences in health behaviours among employees from Britain, Finland and Japan: the influence of psychosocial factors. Health Place 2010;16:61-70.

22 Lahelma E, Pietiläinen O, Ferrie J, et al. Changes over time in absolute and relative socioeconomic differences in smoking: a comparison of cohort studies from Britain, Finland, and Japan. Nicotine Tob Res 2016:18:1697-704.

23 Zaitsu M, Kato S, Kim Y, et al. Occupational Class and Risk of Cardiovascular Disease Incidence in Japan: Nationwide, Multicenter, Hospital-Based Case-Control Study. J Am Heart Assoc 2019;8:e011350.

24 Inoue M, Tsurugano S, Yano E. Job stress and mental health of permanent and fixed-term workers measured by effort-reward imbalance model, depressive complaints, and clinic utilization. $J$ Occup Health 2011;53:93-101.

25 Mezuk B, Ratliff S, Concha JB, et al. Stress, self-regulation, and context: evidence from the health and retirement survey. SSM Popul Health 2017;3:455-63. 
26 Zaitsu M, Cuevas AG, Trudel-Fitzgerald C, et al. Occupational class and risk of renal cell cancer. Health Sci Rep 2018;1:e49.

27 Zaitsu M, Kaneko R, Takeuchi T, et al. Occupational class and male cancer incidence: nationwide, multicenter, hospital-based casecontrol study in Japan. Cancer Med 2019;8:795-813.

28 Ichikawa M, Inada $\mathrm{H}$, Hori $\mathrm{A}$, et al. Tobacco advertising during the COVID-19 pandemic in Japan. J Epidemiol 2021;31:451-2.

29 Hori A, Tabuchi T, Kunugita N. Rapid increase in heated tobacco product (HTP) use from 2015 to 2019: from the Japan 'Society and New Tobacco' Internet Survey (JASTIS). Tob Control 2021;30:474-5.

30 Sutanto E, Miller C, Smith DM, et al. Concurrent daily and NonDaily use of heated tobacco products with Combustible cigarettes: findings from the 2018 ITC Japan survey. Int J Environ Res Public Health 2020;17:2098.

31 Yeager DS, Krosnick JA. The validity of self-reported nicotine product use in the 2001-2008 National health and nutrition examination survey. Med Care 2010;48:1128-32.

32 Kim Y, Zaitsu M, Tsuno K, et al. Occupational differences in Creactive protein among working-age adults in South Korea. $J$ Occup Environ Med 2020;62:194-201.

33 Hori $\mathrm{A}$, Mizoue T, Kasai $\mathrm{H}$, et al. Body iron store as a predictor of oxidative DNA damage in healthy men and women. Cancer Sci 2010;101:517-22. 